\title{
Nomenclature in Abdominal Wall Hernias: Is It Time for Consensus?
}

\author{
Samuel G. Parker ${ }^{1} \cdot$ Christopher P. J. Wood $^{1} \cdot$ David L. Sanders $^{2}$ • \\ Alastair C. J. Windsor ${ }^{1}$
}

Published online: 1 May 2017

(C) The Author(s) 2017. This article is an open access publication

\begin{abstract}
Abdominal wall reconstruction is a rapidly evolving area of surgical interest. Due to the increase in prevalence and size of ventral hernias and the high recurrence rates, the academic community has become motivated to find the best reconstruction techniques. Whilst interrogating the abdominal wall reconstruction literature, we discovered an inconsistency in hernia nomenclature that must be addressed. The terms used to describe the anatomical planes of mesh implantation 'inlay', 'sublay' and 'underlay' are misinterpreted throughout. We describe the misinterpretation of these terms and give evidence of where it exists in the literature. We give three critical arguments of why these misinterpretations hinder advances in abdominal wall reconstruction research. The correct definitions of the anatomical planes, and their respective terms, are described and illustrated. Clearly defined nomenclature is required as academic surgeons strive to improve abdominal wall reconstruction outcomes and lower complication rates.
\end{abstract}

\section{Introduction}

The repair of complex ventral hernias (CVHs) is a rapidly evolving area of surgical interest. Complex hernias are becoming both increasingly prevalent [1] and challenging [2], with a consequent need for the academic hernia community to produce robust research to guide best practice. It is clear when reviewing the CVH repair literature that the nomenclature is used with significant variability and often incorrectly. For example, the recto-rectus plane is often referred to as the 'inlay' [3,4], 'sublay' [5-8] or 'underlay' [9] plane. The pre-peritoneal layer is often also referred to

Samuel G. Parker

samgparker@nhs.net

1 Department of General and Colorectal Surgery, University College London Hospital, 235 Euston Road, London NW1 2BU, UK

2 Department of General and Upper GI Surgery, North Devon District Hospital, Raleigh Park, Barnstaple, Devon EX31 4JB, UK by all three terms; 'inlay' [10], 'sublay' [11] and 'underlay' [12]. And finally, the intra-abdominal plane is often referred to as 'sublay' [13] or 'underlay' [14, 15].

Attempts to produce evidence to guide the best surgical management of these $\mathrm{CVH}$ repairs is already challenging, given the considerable pre-operative and peri-operative variables in these patients. Therefore, it is imperative for surgeons and researchers to use standardised correct nomenclature to prevent misinterpretation, to reduce data heterogeneity and allow for accurate study comparison.

Evidence of inconstancy in the literature: are we using the same language?

As discussed, review of the CVH literature demonstrates multiple examples of inconsistent nomenclature usage. These inconsistencies become of increased concern when these terms are used for intra-operative variable analysis in systematic reviews [15, 16] and meta-analysis [17, 18], which have a greater potential to influence wider clinical 
Table 1 Defining the planes of the anterior abdominal wall

\begin{tabular}{|c|c|c|}
\hline Detailed anatomical description & $\begin{array}{l}\text { Abbreviated anatomical } \\
\text { terms }\end{array}$ & $\begin{array}{l}\text { Ventral hernia } \\
\text { nomenclature/colloquial } \\
\text { terminology }\end{array}$ \\
\hline Mesh is laid on top of the external oblique over the defect & Subcutaneous/onlay/overlay & Onlay/overlay \\
\hline $\begin{array}{l}\text { Mesh is the same size as the hernia defect and the edges are sutured the hernia } \\
\text { neck }\end{array}$ & $\begin{array}{l}\text { Inlay/interposition (always } \\
\text { bridging) }\end{array}$ & Inlay (always bridging) \\
\hline Posterior to the rectus muscles and anterior to the posterior rectus sheath ${ }^{\mathrm{a}}$ & Retro-rectus & Sublay \\
\hline Anterior to the peritoneum and posterior the rectus sheath ${ }^{\mathrm{b}}$ & Pre-peritoneal & Underlay \\
\hline $\begin{array}{l}\text { Mesh is inserted into the Abdominal compartment and laid on the anterior } \\
\text { abdominal wall deep to the peritoneum. Often bridging especially in } \\
\text { laparoscopic surgery }\end{array}$ & $\begin{array}{l}\text { Intra-abdominal/intra- } \\
\text { peritoneal onlay mesh } \\
\text { (IPOM) }\end{array}$ & Intra-peritoneal/(IPOM) \\
\hline
\end{tabular}

${ }^{a}$ Below the arcuate line this layer is between the rectus abdominis muscles and the transversalis fascia. After TAR this layer extends laterally between the transversalis fascia (posteriorly) and the transversus abdominis muscle (anteriorly)

b Below the arcuate line the peritoneum is posterior and the transversalis fascia is anterior. Lateral to the posterior rectus sheath this layer is between the peritoneum (posteriorly) and the transversalis fascia (anteriorly)

Fig. 1 [31] Illustration clearly showing the planes of the anterior abdominal wall



practice. In a much-cited Cochrane review [16], 5 RCTs [19-23] are meta-analysed to compare local wound complication rates of open 'sublay' repairs versus laparoscopic repairs. Critical analysis shows that in two [20,23] of the RCTs the mesh was in fact inserted in the 'underlay' plane, i.e. pre-peritoneal and not retro-rectus (see Table 1; Fig. 1). As a result, this review pools RCTs with open sublay and underlay repairs into a larger 'sublay' group and compares their local wound complication rates to laparoscopic repair. The evidence must therefore be interpreted with some caution as the premise is misguided and wrongly assumes that all five trials used an open technique with the mesh in the 'sublay' rectro-rectus plane.

Further interrogation of the literature reveals other examples of error stemming from nomenclature inconsistencies. A meta-analysis comparing onlay and sublay hernia repairs includes one study [24] that does not use the sublay plane at all, being reported as 'underlay' in the original paper. For a genuine sublay versus onlay metaanalysis, this RCT should have been omitted. Many other examples of the inconsistent use of the nomenclature exist, but these examples demonstrate our point that mixing up the mesh planes in meta-analysis increases heterogeneity and leads to misleading outcomes.

\section{Why is the nomenclature important?}

Precise nomenclature describing the abdominal wall planes is important for three reasons. Firstly, the position of the mesh affects the mechanisms of hernia recurrence. For 
example, intra-abdominal and pre-peritoneal meshes are placed posterior to the transversalis fascia. Consequently, there is a potential for failure at the mesh-fascia interface and for hernia recurrence via either 'lateral detachment of the mesh' or 'inadequate mesh fixation'. These two mechanisms of recurrence also exist for implanted inlay mesh but not for mesh placed in the sublay and onlay planes [25]. Each mesh plane has its own individual set of mechanisms of recurrence, and therefore each plane should be considered independently and not grouped together when analysed.

Secondly, the literature already reports that all post hernia repair complication rates (not just recurrence) are influenced by where the mesh is placed [15, 17]. For example, intra-abdominal mesh exposed to abdominal viscera increases the risk of adhesions, bowel obstruction and fistula formation [26, 27]; onlay mesh placement is associated with higher wound infection rates [15, 17] and hernia recurrence rates are reduced with the mesh in the retro-rectus (sublay) position $[17,26]$. As evidence to guide clinical practice emerges, precise and consistent nomenclature is essential to interpret complication rates relative to the respective anatomical plane.

Lastly, the biomechanics of the abdominal wall are complex. The multiple fascial (collagen) and muscular (muscle fibres) layers each have their own elasticity, tensile strength and anisotropic configuration [28, 29]. Meshes are clearly not as dynamic and shear forces occur at the points of mesh fixation. This causes tearing of collagen and muscle fibres with subsequent defects and hernia recurrence [28, 30]. Research is therefore required to reduce these shear forces and maximise the physiological function of the abdominal wall post repair. Physiological meshes need to be synthesised and placed in specific anatomical planes. This will allow us to identify optimal mesh fixation techniques and to study the forces that occur between the mesh and the adjacent in vitro abdominal wall layers.

\section{Correct nomenclature: unified approach based on anatomical accuracy}

We recommend that consistent nomenclature is used, based on a detailed appreciation of the abdominal wall anatomy. The correct anatomical description of the mesh planes in the abdominal wall is shown in Table 1 and Fig. 1 [31]. This has been described in the literature $[32,33]$ but has never been laid out in such detail. This anatomical description is shown with the correct abbreviated anatomical terms. The correct nomenclature or 'colloquial' terminology is also defined [32, 33].

\section{Conclusion}

The repair of $\mathrm{CVH}$ is a challenging area in both surgical practice and surgical research. Inconsistencies in the understanding of the nomenclature and the anatomy are leading to flaws in the data. This has the potential to be misleading and generate spurious evidence. We recommend that a consistent nomenclature based on an appreciation of the anatomy is used. This will aim to ensure that not only is the clinical management consistent, but allows for a transparent and unified evidence base for these complex surgical cases.

\section{Compliance with ethical standards}

Conflict of interest S.G. Parker and C.P.J. Wood have no conflict of interest. D. Sanders declares conflicts of interest not directly related to the submitted work; A. Windsor declares conflicts of interest not directly related to the submitted work.

Open Access This article is distributed under the terms of the Creative Commons Attribution 4.0 International License (http://crea tivecommons.org/licenses/by/4.0/), which permits unrestricted use, distribution, and reproduction in any medium, provided you give appropriate credit to the original author(s) and the source, provide a link to the Creative Commons license, and indicate if changes were made.

\section{References}

1. Poulose BK, Shelton J, Phillips S, Moore D, Nealon W, Penson D, Beck W, Holzman MD (2012) Epidemiology and cost of ventral hernia repair: making the case for hernia research. Hernia 16(2):179-183

2. Scheuerlein H, Settmacher U, Lenschow M, Rauchfuss F (2016) Complex incisional hernias. Arch Clin Gastroenterol 2(1):017-026

3. Ascencio F, Aguilo J, Peiro S, Carbo J, Ferri R, Caro F, Ahmad M (2009) Open randomized clinical trial of laparoscopic versus open incisional hernia repair. Surg Endosc 23:1441-1448

4. Henry CR, Bradburn E, Moyer KE (2013) Complex abdominal wall reconstruction: an outcomes review. Ann Plast Surg 71(3):266-268

5. Navarra G, Musolino C, De Marco ML, Bartolotta M, Barbera A, Centorrino T (2007) Retromuscular sutured incisional hernia repair. A randomized controlled trial to compare open and laparoscopic approach. Surg Laparosc Endosc Percutan Tech 17(2):86-90

6. Rickert A, Kienle P, Kuthe A, Baumann P et al (2012) A randomised, multi-centre, prospective, observer and patient blind study to evaluate a non-absorbable polypropylene mesh vs. a partly absorbable mesh in incisional hernia repair. Langenbecks Arch Surg 397:1225-1234

7. Bessa SS, El-Gendi AM, Ghazal AHA et al (2015) Comparison between the short term results of onlay and sublay mesh placement in the management of uncomplicated para-umbilical hernia: a prospective randomized study. Hernia 19:141-146

8. Petro CC, Como JJ, Yee S et al (2014) Posterior component separation and transversus abdominis muscle release for complex incisional hernia repair in patients with a history of an open abdomen. J Trauma Acute Care Surg 78(2):422-429 
9. Slater NJ, Van der Kolk M, Hendriks T, Van Goor H, Bleichrodt RP (2013) Biologic grafts for ventral hernia repair: a systematic review. Am J Surg 205:220-230

10. Olmi S, Scaini A, Cesana GC, Erba L, Croce E (2007) Laparoscopic versus open incisional hernia repair: an open randomized controlled study. Surg Endosc 21:55-559

11. Abdo-Ryia MH, El-Khadrawy OH, Moussa GI, Saleh AM (2015) Prospective randomized evaluation of open preperitoneal versus preaponeurotic primary elective mesh repair for paraumbilical hernias. Surg Today 45:429-433

12. Okusanya OT, Scott MF, Low DW, Morris JB (2014) The partial underlay preperitoneal with panniculectomy for incisional abdominal hernia in the morbidly obese. Surg Obes Relat Dis 10(3):495-501

13. Pring CM, Tran V, O'Rourke N, Martin IJ (2008) Laparoscopic versus open ventral hernia repair: a randomized controlled trial. ANZ J Surg 78:903-906

14. De Vries Reilingh TS, Van Goor H, Chardon JA, Rosman C et al (2007) Repair of giant midline abdominal wall hernias: "components separation technique" versus prosthetic repair. World J Surg 31:756-763. doi:10.1007/s00268-006-0502-x

15. Holihan JL, Nguyen DH, Nguyen NT, Mo J, Kao LS et al (2016) Mesh location in open ventral hernia repair: a systematic review and network meta-analysis. World J Surg 40:89-99. doi:10.1007/ s00268-015-3252-9

16. Sauerland S, Walgenbach M, Habermalz B, Seiler CM, Miserez M (2011) Laparoscopic versus open surgical techniques for ventral or incisional hernia repair. Cochrane Database Syst Rev. doi:10.1002/14651858.CD007781.pub2

17. Timmermans L, De Goede B, Van Dijk S, Kleinrensink G, Jeekel J, Lange JF (2014) Meta-analysis of sublay versus onlay mesh repair in incisional hernia surgery. Am J Surg 207:980-988

18. Timmermans L, De Goede B, Eker H, Van Kempen B, Jeekel J, Lange JF (2013) Meta-analysis of primary mesh augmentation as prophylactic measure to prevent incisional hernia. Dig Surg 30:401-409

19. Buunen M, Hansson BME, Nieuwenhuizen J, Jeekel J (2009) Laparoscopic versus open hernia repair: a mulit-center clinical trial. Surg Endosc 23(suppl 1):S2

20. Carbajo MA, Martin del Olmo JC, Blanco JI, de la Cuesta C, Toledano M, Martin F, Vaquero C, Inglada L (1999) Laparoscopic treatment vs open surgery in the solution of major incisional and abdominal wall hernias with mesh. Surg Endosc 13(3):250-252

21. Misra MC, Bansal VK, Kulkarani MP, Pawar DK (2006) Comparison of laparoscopic and open repair of incisional and primary ventral hernia: results of a prospective randomised study. Surg Endosc 20(12):1839-1845
22. Navarra G, Musolino C, De Marco ML, Bartolotta M, Barbera A, Centorrino T (2007) Retromuscular sutured incisional hernia repair: a randomised controlled trial to compare open and laparoscopic approach. Surg Lap Endosc 17(2):86-90

23. Olmi S, Scaini A, Cesana GC, Erba L, Croce E (2007) Laparoscopic versus open incisional hernia repair: an open randomized controlled study. Surg Endosc 21(4):555-559

24. De Vries Reilingh TS, van Geldere D, Langenhorst B et al (2004) Repair of large midline incisional hernias with polypropylene mesh: comparison of three operative techniques. Hernia 8:56-59

25. Awad ZT, Puri V, LeBlanc K, Stoppa R, Fitzgibbons RJ, Iqbal A, Filipi CJ (2005) Mechanisms of ventral hernia recurrence after mesh repair and a new proposed classification. J Am Coll Surg 201(1):132-140

26. Albino FP, Patel KM, Nahabedian MY, Sosin M, Attinger CE, Bhanot P (2013) Does mesh location matter in abdominal wall reconstruction? A systematic review of the literature and a summary of the recommendations. Plast Reconstr Surg 132(5):1294-1304

27. Snyder CW, Graham LA, Gray SH, Vick CC, Hawn MT (2011) Effect of mesh type and position on subsequent abdominal operations after incisional hernia repair. J Am Coll Surg 212(4):496-502

28. Anurov MV, Titkova SM, Oettinger AP (2012) Biocompatibility of surgical mesh and fascia being reinforced: dependence of experimental hernia defect repair results on anisotropic surgical mesh positioning. Hernia 16:199-210

29. Grasa J, Sierra M, Lauzeral N, Munoz MJ, Miana-Mena FJ, Calvo B (2016) Active behaviour of abdominal wall muscles: experimental results and numerical model formulation. J Mech Behav Biomed Mater 61:444-454

30. Smietanski M, Bury K, Tomaszewska A, Lubowiecka I, Szymczak C (2012) Biomechanics of the front abdominal wall as a potential factor leading to recurrence with laparoscopic ventral hernia repair. Surg Endosc 26:1461-1467

31. Winkler MS, Gerharz E, Dietz UA (2008) Narbenhernienchirurgie. Ubersicht und aktuelle Trends (Overview and evolving strategies of vnetral hernia repair). Urologe A 47(6):740-747

32. Dietz UA, Hamelmann W, Winkler MS, Debus ES, Malafaia O, Czeczko NG, Thiede A, Kuhfuss I (2007) An alternative classification of incisional hernias enlisting morphology, body type and risk factors in the assessment of prognosis and tailoring of surgical technique. J Plast Reconstr Aesthet Surg 60:383-388

33. Muysoms F, Campanelli G, Champault GG, Debeaux AC, Dietz UA, Jeekel J, Klinge U, Kockerling F, Mandala V, Montgomery A, Morales Conde S, Puppe F, Simmermacher RKJ, Smietanski M, Miserez M (2012) EuraHS: the development of an international online platform for registration and outcome measurement of ventral abdominal wall hernia repair. Hernia 16:239-250 